\title{
CONTAÇÃO DE HISTÓRIAS, EM/COM LIBRAS, NO YOUTUBE
}

\author{
Adriana Moreira de Souza Corrêa ${ }^{1}$ \\ Antonio Joamir Brito do Nascimento ${ }^{2}$
}

\begin{abstract}
Resumo: As histórias divulgadas nos meios digitais contribuem para a inserção de outras línguas e linguagens como semioses que permeiam as novas práticas de leitura. Neste trabalho, trataremos de canais do Youtube que disponibilizam essas histórias, gratuitamente, utilizando-se da Língua Brasileira de Sinais - Libras e/ou do Português como línguas que expressam as narrativas. Para tanto, descreveremos dez canais que se enquadram nessas características, os quais classificamos em três grupos: somente em Libras, com Libras em primeiro plano, com Libras em segundo plano, de modo a identificar as contribuiçôes dessas histórias para as práticas escolares e não escolares. Trata-se de uma pesquisa exploratória, pautada na revisão bibliográfica e na análise de canais que se mostraram produtivos por conterem 141 histórias, em vários gêneros, que podem promover a aquisição da língua, acesso ao repertório cultural de determinado grupo e ampliar o conhecimento de si e do mundo nas pessoas surdas, além de divulgar a Libras, estimular o aprendizado pelo surdo e a inclusão.
\end{abstract}

Palavras-chave: Histórias em Libras. Contação. YouTube.

\section{STORYTELLING, IN/WITH POUNDS, ON YOUTUBE}

\begin{abstract}
Stories published in digital media contribute to the insertion of other languages as semiosis that permeate new reading practices. This paper aims to approach about YouTube channels that make these stories available, free of charge, using Brazilian Sign Language - Libras and / or Portuguese as languages that express the narratives. Ten channels that fit these characteristics were described, which were classified into three groups: only in Libras, with Libras in the foreground and with Libras in the background, in order to identify the contributions of these stories to school and nonschool practices. This is an exploratory research, based on the bibliographical review and analysis
\end{abstract}

1 Graduada em Pedagogia pela Universidade Federal do Ceará (2004); Especialista em Educação Especial pela Universidade Federal do Ceará (2014); Professora de Língua Brasileira de Sinais na Universidade Federal de Campina Grande; aluna do mestrado em ensino na Universidade Estadual do Rio Grande do Norte.

2 Graduado em Educação Física pela Universidade Federal do Ceará (2004); Mestre em Educação Brasileira pela Universidade Federal do Ceará. 
of channels identified as productive by telling 141 stories of varied genres that can promote the language acquisition, access to the cultural repertoire of a certain group and increase the knowledge of oneself and the deaf people, in addition to publicizing the Libras, stimulating learning by the deaf and inclusion.

Keywords: Stories in Sign Language. Story Telling. YouTube.

\section{INTRODUÇÃO}

A contação de histórias é uma prática que permeia a vida dos seres humanos desde a infância e perpassa diferentes idades e, para isso, se utiliza de mediadores diversos (livros, contadores entre outros). O momento da contação se concretiza na interação entre o contador e o expectador e, para atingir o objetivo, precisa considerar as competências comunicativas desses interlocutores. Isso implica que o mediador precisa considerar tanto as habilidades de quem conta a história, quanto a idade, o conhecimento prévio e até mesmo a língua natural do receptor do texto.

Neste sentido, sabendo que a pessoa surda se utiliza da Língua Brasileira de Sinais - Libras como principal sistema de comunicação, suas interações com os utentes da Língua Portuguesa tendem a ser limitadas em função de se tratar de uma segunda língua e isso pode implicar na dificuldade de participar deste momento que permeia a cultura ocidental. Com isso, são impostas barreiras para que ela possa incorporar no seu repertório pessoal, as histórias que são conhecidas pelas demais crianças ouvintes de mesma idade.

Diante disso, surgiu a inquietação de buscar alternativas que possibilitem o acesso das crianças surdas ao processo de contação de histórias e, para tanto, buscamos identificar instrumentos que favoreçam a inserção do surdo no universo das histórias de modo a proporcionar-lhe situações que estimulem o letramento literário em espaços escolares além de viabilizar o acesso a esses artefatos culturais em ambientes de educação informal.

Sabemos que apesar de ser oriunda da tradição oral, as técnicas e os meios de contação vêm se diversificando com o avanço tecnológico. Assim, além da tradicional leitura do livro ou a contação sem a utilização de um suporte vemos outros recursos auxiliarem ou substituírem o componente humano (de forma presencial) no processo de contação os quais destacamos: os vídeos e áudios disponíveis em CDs e DVDs que acompanham alguns livros ou mesmo os sites da internet que são disponibilizadas diferentes histórias.

Em face do exposto, realizamos uma investigação no site de compartilhamento de vídeos YouTube, no sentido de apresentar alguns canais que disponibilizam histórias em Libras ou acessíveis nesta língua, a fim de discutir o uso social desses textos para a formação do surdo e na ampliação do uso da Libras em diferentes espaços sociais.

Com esse intuito, realizamos uma busca no YouTube utilizando os seguintes descritores contação + história + Libras e selecionamos 10 canais que apresentavam vídeos em Libras sinalizados por usuários da Libras fluentes. 
Assim a investigação em tela trata de uma pesquisa exploratória, pois busca produzir maior familiaridade com o tema proposto. Para tanto, utilizamos a pesquisa bibliográfica associada à análise de canais do YouTube que disponibilizam contações de histórias em Libras ou com tradução para esta língua. A discussão divide-se em 3 seções: Contação de histórias e formação humana; Literatura na web e Libras e Literatura no mundo Digital que serão descritos a seguir.

\section{CONTAÇÃO DE HISTÓRIA E FORMAÇÃO HUMANA}

$\mathrm{O}$ ato de contar histórias nos remete às reuniões de seres humanos que à luz das fogueiras apresentavam explicações fabulosas para fenômenos da natureza que despertavam o interesse das pessoas. Para Cavalcanti (2002, p. 28),

[...] esses relatos estavam impregnados de conteúdos voltados para o sobrenatural, o misterioso envolvido na aura do sagrado. Eram relatos marcados pelo registro de rituais de iniciação e magia, próximos à consciência mítica e religiosa, para, somente muito tempo depois, transformarem-se em mito e história.

$\mathrm{Na}$ Idade Média, essa prática recebeu um valor pedagógico e moral, sendo redimensionado apenas no século XIX, quando os Irmãos Grimm divulgaram os recontos apropriados para as crianças. Já no século XX, a contação de histórias passa a ser vista como uma prática lúdica (valorizando o prazer e a fruição), como também enquanto recurso pedagógico (VALLE, 2016). Com isso, identificamos que esta prática perpassa os séculos e, mesmo assumindo funções diferentes, continua a permear as interações cotidianas.

Assim, como informa a autora, a contação de histórias parte da tradição oral e, ainda hoje, podemos encontrar marcas desta forma de interação humana presentes em diferentes relações, tanto familiares quanto escolares. Corroborando com Candido (2002), Giordano (2013, p. 41) diz que:

[...] quando pensamos a arte de contar histórias a associamos à humanização
dos humanos, já que o homem não nasce humanizado ele se humaniza, e
com isso, queremos dizer que ela (a arte de narrar) se insere numa dimensão
formativa, isto é, a dimensão que aborda o desenvolvimento harmonioso do
ser humano em todos os seus aspectos: razão, emoção, corpo e espírito.

Ainda para a autora, o ato de contar histórias contribui com o processo de simbolização, com a abstração e a capacidade criadora, por isso, faz-se necessário proporcionar diferentes espaços de acesso à literatura por meio da arte da contação. Através dessa relação, é possível "apresentar o mundo das diferentes culturas, pois se trata de oportunizar a apropriação (que o ouvinte faz) da palavra do contador, dando sentido a ela e integrando-a em seu universo pessoal psicoafetivo" (GIORDANO, 2013, p. 31). A investigadora acrescenta que, através destes textos, o indivíduo internaliza a cultura e também desenvolve estratégias para lidar com os conflitos que se apresentam na história e no seu cotidiano. 
Essa forma de representação humana do mundo se faz presente na literatura e se manifesta na ação de ler uma obra e permitir-se compreender os sentimentos da personagem ou mesmo se faz presente no ato de refletir sobre situações da própria vida, com as quais a trama possibilita o distanciamento necessário para buscar soluções possíveis no mundo real.

Candido (2002) ressalta que a necessidade do ser humano pela ficção é manifestada incessantemente em diferentes ações sociais. Para o autor, desde o momento em que imaginamos o desfecho de uma situação vivenciada, estamos fazendo uso da ficção, assim, este vínculo entre fantasia e realidade se torna presente nas ações cotidianas. Ainda para o estudioso,

A literatura pode formar, mas não segundo a pedagogia oficial, que costuma vê-la ideologicamente como um veículo da tríade famosa - o Verdadeiro, o Bom, o Belo, definidos conforme os interesses dos grupos dominantes, para reforço da sua concepção de vida. Longe de ser um apêndice da instrução moral e cívica (esta apoteose matreira do óbvio, novamente em grande voga), ela age com o impacto indiscriminado da própria vida e educa como ela com altos e baixos, luzes e sombras (CANDIDO, 2002, p. 83, grifo do autor).

O investigador nos adverte também que essas informações explícitas e implícitas podem ativar percepções e sentimentos nas "camadas mais profundas da nossa personalidade" (CANDIDO, 2002, p. 83) deixando marcas profundas que nem sempre podem ser percebidas ou sentidas. Nesse contexto, inferimos que ao passo que a leitura é significada pelos conhecimentos prévios do leitor, essas informações modificam a percepção dele sobre si e sobre o mundo sendo, portanto, de grande relevância para o indivíduo.

Em face do exposto, compreendemos o papel relevante da literatura na composição do repertório cultural do ser humano, na construção de si, nas formas de intervir e interagir no mundo. Ao mesmo tempo, a literatura também pode funcionar como instrumento de internalização ou de reflexão sobre a cultura. Desse modo, compreendendo que $95 \%$ das pessoas surdas nascem em famílias de pessoas ouvintes (SLOMSKI, 2010), o processo de contação de histórias e apropriação dos conhecimentos mediados por ela pode ser prejudicado devido ao contador e ao apreciador não compartilharem uma língua. Diante disso, os sites que disponibilizam a contação de histórias em/com Libras podem se configurar como um recurso que contribui para a internalização da Língua de Sinais (pelas crianças, familiares e educadores); para a interação entre as pessoas envolvidas no processo de contação; para o acesso à uma bagagem cultural compartilhada entre ouvintes e surdos, para a autorreflexão sobre aspectos da vida, bem como para desenvolver o prazer e a fruição através do acesso às histórias.

\section{LITERATURA NA WEB E LIBRAS}

A expansão do uso do meio digital, possibilitada pelos diferentes aparelhos (seja de telefonia, computadores ou tablets) ensejou uma nova relação do leitor com o texto. Para Vieira (2007) e Rojo (2012), ler na atualidade envolve diferentes 
modalidades da linguagem que ultrapassam o uso da escrita. As autoras afirmam que ler, nos dias de hoje, significa integrar diferentes modalidades, tais como a imagem (estática e/ou em movimento), a fala, a música entre outros, permitindo o desenvolvimento de textos multissemióticos. Essa perspectiva de compreensão e construção de textos ampliou as possibilidades de interação não só entre as diferentes semioses quanto entre as línguas envolvidas na sua produção. Com isso, neste trabalho, destacaremos a utilização dos textos que inserem o bilinguismo (envolvendo Libras e Língua Portuguesa) no uso da comunicação em sinais em contações de histórias disponíveis na internet.

Para Marcuschi (2008, p.78), "O texto se dá como um ato de comunicação unificado num complexo universo de ações alternativas e colaborativas". Neste sentido, Fávero e Koch (2009) complementam asseverando que, no sentido lato, o texto se concretiza em qualquer tipo de manifestação da textualidade humana, utilizando-se, para tanto, de qualquer mediação semiótica. Sobre a textualidade, Marcuschi (2008) explica que é a significação relacionada aos aspectos contextuais (no interior do texto) e contextuais (que nos remetem aos conhecimentos externos que nos possibilitam interpretá-los).

Esta concepção de contação de história advém da compreensão de que o texto é um produto da relação de comunicação entre um sujeito historicamente situado (autor) que interage, por meio do texto com outro sujeito que também é fruto das relações temporais e espaciais. Por isso, considerando o reconhecimento da Libras, por meio da Lei $n^{\circ} 10.436 / 2002$, vemos a relevância de buscar recursos que permitam o acesso às diferentes histórias pelos usuários dessa língua. A Libras é definida no Parágrafo único, do Art. $1^{\circ}$ da referida legislação, como um sistema linguístico que se utiliza da modalidade visual-motora para expressão e compreensão de ideias e fatos pelas pessoas surdas brasileiras. No entanto, é ressaltado, na mesma lei, que a modalidade escrita da Língua Portuguesa não deve ser desconsiderada pelo surdo, tendo em vista que ele precisa se constituir como um indivíduo bilíngue para participar de relações sociais que podem ser mediadas por ambas as línguas.

Devido à característica visual desse sistema linguístico, as tecnologias de gravação de vídeo contribuíram para acessibilizar as histórias inserindo a Libras como uma língua de comunicação (para as histórias produzidas em Libras) ou como sistema linguístico secundário ao se tratar das situações nas quais a história foi traduzida. Apesar de, em ambas as situações, a pessoa surda pode se apropriar do conteúdo da história, àquelas contadas por meio da Libras, permitem uma aproximação maior entre o contador e o expectador, tendo em vista que, esta última é mais adequada à pessoa surda. $\mathrm{O}$ texto traduzido implica na inserção do leitor usuário da Libras, mas o coloca em segundo plano, à medida que a contação é expressa por um utente da Língua Portuguesa.

Pereira et al. (2013, p. 5) definem a Libras como um sistema linguístico “[...] de modalidade visual-gestual (ou visual-espacial), uma vez que a informação linguística é recebida pelos olhos e produzida no espaço, pelas mãos, pelo movimento do corpo e pela expressão facial." Com isso, destacamos as mídias de registro em vídeo 
como aquelas que contribuem significativamente para a difusão das histórias e da Língua de Sinais. Entre estas mídias, destacamos a web, como espaço que permite o registro de mensagens por meio da imagem em movimento e encontra no YouTube, um domínio democrático de divulgação dessas produções.

Esses vídeos compreendem produções de diferentes conteúdos e diversos gêneros que recebem características específicas ao serem inseridos no meio digital. Surge, assim, o que Rojo (2012) e Marcuschi (2010) denominaram de gêneros digitais, que são aqueles produzidos e divulgados no meio digital. Os textos ora trabalhados ao serem inseridos neste espaço virtual, recebem características de composição diferenciadas, tais como a possibilidade de inserção de outras semioses produzindo, desse modo, novas formas de leitura.

Para Soares (2002, p. 96):

A tela, como novo espaço de escrita, traz significativas mudanças nas formas de interação entre escritor e leitor, entre escritor e texto, entre leitor e texto e, até mesmo, mais amplamente, entre o ser humano e o conhecimento. [...] A hipótese é de que essas mudanças tenham consequências sociais, cognitivas e discursivas, e estejam, assim, configurando um letramento digital, isto é, um certo estado ou condição que adquirem os que se apropriam da nova tecnologia digital e exercem práticas de leitura e de escrita na tela, diferente do estado ou condição - do letramento - dos que exercem práticas de leitura e de escrita no papel.

As contações de história presentes no YouTube são, em sua essência, gêneros multimodais. Para Santos (2008, p. 77):

[...] na multimodalidade, a maioria dos textos envolve um complexo jogo entre textos escritos, cores, imagens, elementos gráficos e sonoros, o enquadramento, a perspectiva da imagem, espaços entre imagem e texto verbal, escolhas lexicais, com predominância de um ou de outro modo, de acordo com a finalidade da educação, sendo, portanto, recursos semióticos importantes na construção de diferentes discursos.

Essas habilidades requerem letramentos múltiplos, que possibilitem ao leitor significar a mensagem a partir da interação dessas diferentes semioses. Diante disso, conforme destaca Figueiredo e Guarinello (2013, p. 177):

[...] os multiletramentos ou letramentos múltiplos, inclusive os letramentos das culturas locais e de seus agentes, colocando-os em contato com os letramentos valorizados, universais e institucionais; os letramentos multissemióticos, ampliando a noção de letramento para o campo da imagem, da música e das outras semioses que não somente a escrita;

Ainda para as autoras, ao tratar desses recursos digitais, é necessário considerar os suportes e as mídias disponíveis no meio digital para permitir o acesso a esses textos que são construídos utilizando-se de linguagens diversas. "Isso porque, a Internet, por sua estrutura hipertextual, articula espaços de informação à ferramentas de comunicação, propondo um conjunto de dispositivos interativos que 
dão lugar a novos escritos, instantaneamente publicados e lidos." (FIGUEIREDO; GUARINELLO, 2013, p. 178).

As investigadoras ressaltam que a multimodalidade e multissemiose possibilitam a participação do surdo nas atividades realizadas em sala, inserindoos em práticas letradas. Como vimos nos textos, essas práticas podem envolver a Libras e a leitura dos elementos visuais presentes nos textos ou mesmo ensejar o aprendizado da Língua Portuguesa ao propiciar o contato do surdo com este sistema linguístico.

Ainda para as investigadoras, o contador, além das técnicas de contação que visam prender a atenção e despertar a emoção, preocupam-se com os figurinos, maquiagem, o uso da tecnologia, contudo, três elementos permanecem: a necessidade do contador, o texto, o suporte no qual é veiculado e o expectador (ouvinte ou surdo).

\section{LITERATURA NO MUNDO DIGITAL}

Os textos (em vídeo) produzidos em Libras compreendem as produções realizadas tendo como foco a língua natural do surdo. Carneiro (2012, p. 243) identificou "[...] a formação do que chamamos webliteratura, uma modalidade da escrita que confere ao texto características próprias potencializadas pela internet e o universo virtual". Apesar da maioria dos vídeos não serem compostos na modalidade escrita da língua, as produções em Libras, ou vertidos para esta língua podem se enquadrar nestas características à medida que requerem formas específicas de produções sinalizadas. Essas formas se revelam seja no uso do espaço de sinalização ou nos movimentos do contador de histórias que são influenciadas pelo enquadramento da filmagem e pelas características da produção do vídeo: assincronia entre contador e expectador, o espaço utilizado, entre outros.

Marcuschi (2010) destaca que a popularização da internet favoreceu o surgimento de diferentes "escritores" e "leitores" e, neste sentido, porque não dizer contadores e expectadores? $?^{3}$ Carneiro (2012, p. 245) diz que a internet convida à apropriação da "textualidade webliterária - literatura que nasce e circula na web - por meio da qual diferentes atores desempenham diferentes papéis, produzindo o sentido em conjunto". Diante disso, podemos afirmar que esta produção pode ocorrer de maneira monolíngue ou bilíngue. Considerando os surdos, os textos monolíngues precisam priorizar a Libras, já para os ouvintes, a comunicação ocorre, prioritariamente, em Língua Portuguesa. Mas, ao inserir as duas línguas, as contações ocorrem de maneira mais democrática e inclusiva, estimulando a divulgação da Libras.

Além disso, permite a interação entre línguas, inserindo a possibilidade de acesso ao texto pelos surdos (na Libras) e pelos ouvintes (em Português oral e/ou estrito - através da legenda). Neste estudo destacaremos três grupos de produções

3 Optamos pelo termo expectadores para evitar a oposição entre os termos surdo e ouvinte. 
que envolvem: textos traduzidos/contados em Libras, textos em Libras traduzidos para o Português e os textos em Português traduzidos para a Libras.

\subsection{Textos traduzidos/contados em Libras}

Durante a investigação selecionamos quatro canais que apresentam contação em Libras, são eles: o Sistema Chaplin, Rimar Romano, APM CEADA e Elayne Kanashiro. Os critérios de seleção foram a qualidade da sinalização (em aspectos de construção sintática, a fluência do sinalizador e a adequação do uso de pausas, manutenção da interação com o expectador pelo uso da função fática da língua adequada ao gênero) $)^{4}$.

Figura 1 - Cinderela Surda Libras

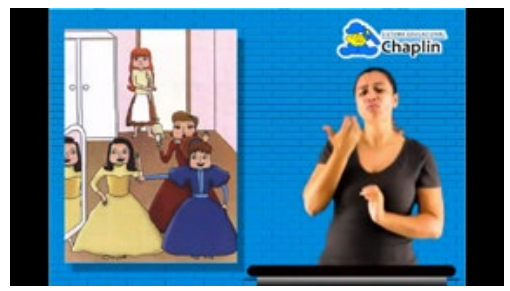

Fonte: Sistema Chaplin (2011).

Figura 2 - Os três machados:

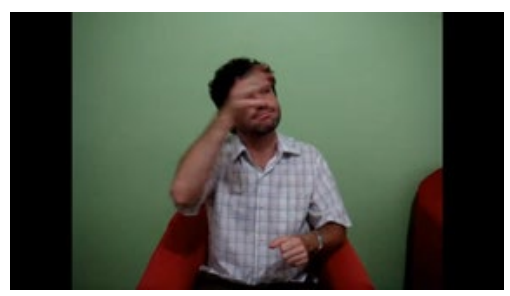

Fonte: Romano (2007).

4 As imagens apresentadas se referem à vídeos de contação de histórias presentes nos sites indicados nas referências. 
Figura 3 - Chapeuzinho Amarelo

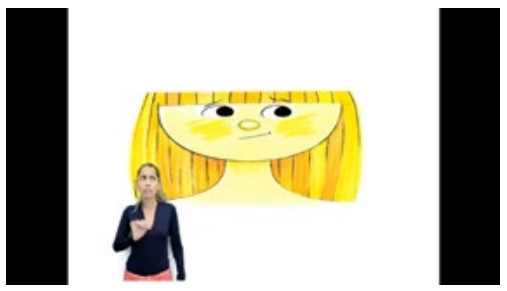

Fonte: APM CEADA (2017).

Figura 4 - A arara e o macaco:

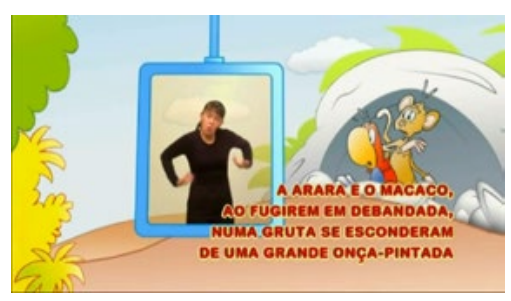

Fonte: Kanashiro (2009).

O vídeo Cinderela Surda é disponibilizado pelo canal do Sistema Chaplin que está no ar desde 13 de outubro de 2011. Como características vimos que ele dispõe apenas da sinalização, que as páginas do livro original que aparece simultaneamente à apresentação em Libras e uma música instrumental ao fundo (figura 1). Para este texto, é requerido um nível de fluência em Libras mais aprofundado, de modo que o leitor possa perceber a informação contida na sinalização. Contudo, ressaltamos que a presença de imagem na composição do significado estimula a apropriação do vocabulário, como também da estrutura da Libras ampliando, assim, a compreensão nesta língua. Utilizando o recurso ora apontado, este processo de apropriação do texto é semelhante ao que acontece com as crianças ouvintes que escutam as histórias contadas pelos seus pais e, dessa maneira, ampliam o repertório cultural bem como se apropriam de um sistema linguístico.

O canal Rimar R. Segalla dispõe de 63 vídeos. Destes, 29 são histórias ou poesias em Libras. Com inscrição datada de 15 de outubro de 2007, dispõe de uma variedade de vídeos, de diferentes gêneros textuais, que podem interessar pessoas de diferentes idades, tais como entrevistas, reportagens, explicações sobre termos ou temáticas, poesias, fábulas, histórias reais entre outras. O contador utiliza-se da Libras e, em alguns vídeos, recorre a figurino ou imagens para favorecer o processo de contação (figura 2) contudo, ao assistir às histórias observamos que as temáticas abordadas, a velocidade da sinalização e a falta de elementos que auxiliem no processo de significação dificultariam a compreensão da mensagem por sinalizantes que apresentam pouca fluência em Libras. 
O canal APM CEADA foi inscrito no YouTube em 12 de agosto de 2014 e não disponibiliza descrição dos objetivos desse espaço digital. Em busca ao blog ${ }^{5}$ associado ao canal, identificamos que CEADA é a sigla usada para Centro Estadual de Atendimento ao Deficiente e de Audiodescrição, que funciona em Campo Grande - MS. O canal traz traduções de música, contações de histórias entre outros gêneros.

Apresenta 45 textos com sinalização em Libras sendo que 23 correspondem a histórias e os demais tratam de diversos temas como convites, traduções de música, explicações de conteúdo em Libras etc. $\mathrm{Na}$ contação, traz como plano de fundo com partes da história e presença da Língua Portuguesa na apresentação da capa (figura 3). Apenas um vídeo mostra o texto em português escrito, predominando, assim, a contação em Libras e a imagem como recursos de significação. Trazem histórias associadas ao contexto infantil, mas podem despertar o interesse de pessoas de diferentes idades, sejam eles usuários da Libras ou aprendizes.

O canal Elayne Kanashiro, inscrito desde 13 de setembro de 2009, apresenta duas histórias em Libras (O leão e a mentira e A arara e o macaco), sendo elas compostas de sinalização e imagens das páginas do livro. Há ainda a versão de uma delas apenas em Libras oportunizando duas formas de apresentação da mesma história. Desse modo, o bilinguismo surge na sinalização mesclada com a presença da Língua Portuguesa na modalidade escrita presente nas páginas do livro, ou em forma de legenda (figura 4).

Esses canais são fundamentais para a autoimagem da pessoa surda, à medida que valoriza a sua língua materna no processo de contação. As relações estabelecidas com as histórias são impregnadas de significados explícitos e implícitos e, entre este último, ressaltamos o incentivo aos surdos, após assistirem às histórias na sua língua, e assim serem contadores das suas próprias histórias ou daquelas internalizadas a partir dos vídeos, seja no ambiente presencial ou virtual.

\subsection{Textos em Libras traduzidos para o Português}

Nesta categoria, discutiremos os textos que apresentam a Libras como língua de contação principal, mas que dispõem da tradução para a Língua Portuguesa. Destacaremos 4 canais, a saber: Mãos Aventureiras, TV INES, TV CES e Librando Histórias.

5 Mais informações em: <http://librasapmceada.blogspot.com/>. Acesso em: 29 maio 2019. 
Figura 5 - Adélia

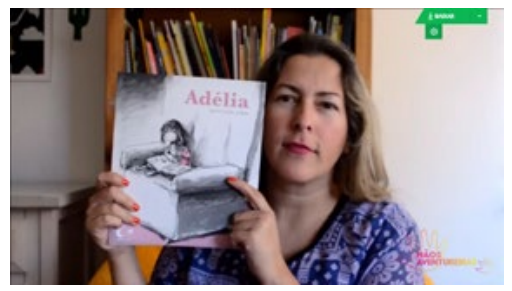

Fonte: Mãos Aventureiras (2017).

Figura 6-Contação de Histórias

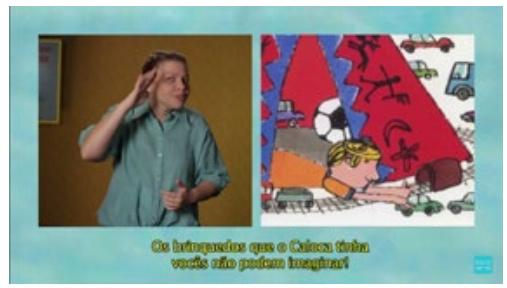

Fonte: TV INES (2013).

Figura 7 - Os três porquinhos

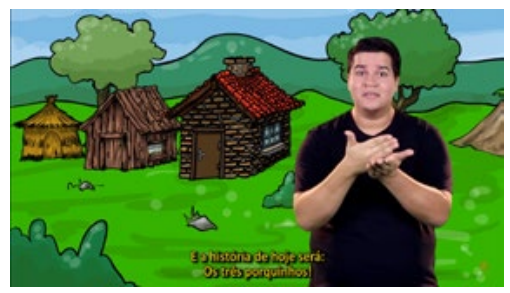

Fonte: TV CES (2016).

Figura $8-7$ ovelhas em Libras

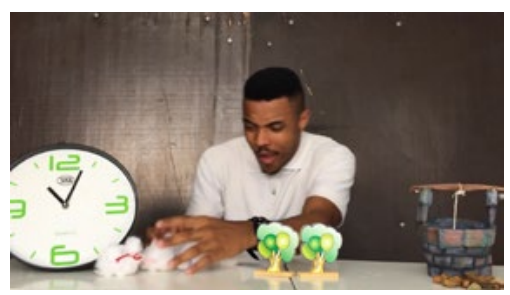

Fonte: Librando Histórias (2018).

O canal "Mãos Aventureiras" iniciou a divulgação de histórias contadas em Libras no dia 05 de setembro de 2017. De acordo com a descrição apresentada 
no próprio site, é a parte integrante de um blog e neste espaço digital há 39 vídeos apresentados em Libras, sendo que, destes, 2 correspondem a sinalizações e 2 à apresentação da contadora e do canal (vinheta). As 35 histórias são contadas em Libras, e são intercaladas com as páginas do livro contendo imagens e o texto em Língua Portuguesa na modalidade escrita (figura 5).

Neste espaço, a Língua Portuguesa aparece como secundária na contação porque o objetivo é a apresentação da sinalização, portanto, o tempo de exibição e a qualidade da imagem das páginas do livro dificultam a leitura do texto em Português. A sinalização é realizada de maneira devagar (pausada) adequada ao público infantil. Paráfrases e expressões corporais são enfatizadas contribuindo para a construção da compreensão e da internalização (em contexto) desses recursos amplamente utilizados na Libras.

A imagem da página do livro, intercalando a sinalização de cada parte da história contada, pode contribuir para que o expectador relacione os sinais e a sinalização às ilustrações. Por esta razão, os textos são recomendados para usuários da Libras ou pessoas em processo de aquisição dessa língua.

O Canal do Instituto Nacional de Educação de Surdos - INES é relacionado à escola bilíngue para surdos localizada no Rio de Janeiro e disponibiliza na programação da TV INES, o quadro denominado "Contação de Histórias". O canal está no ar desde 16 de julho de 2013 e, conforme a sua descrição, pretende ser um canal 100\% bilíngue. Há 28 vídeos que contém 21 contações, pois há algumas histórias que, pela extensão, foram divididas em duas ou três partes. Os textos (lendas, romances e histórias infantis) foram produzidos em uma perspectiva multissemiótica e bilíngue, envolvendo a sinalização, a apresentação de páginas do livro, a legenda e o áudio em Língua Portuguesa (figura 6). A apresentação é semelhante ao espaço digital anteriormente apresentado.

O terceiro canal que destacamos nessa categoria e que apresenta essas características é o TV CES Centro de Educação para Surdos Rio Branco, uma escola de surdos situada em Cotia - SP. Este canal foi cadastrado em 30 de maio de 2016 e contém um espaço específico para esses textos que é denominado de Histórias. Nele, podemos encontrar cinco histórias, divididas assim: três lendas e dois contos.

As histórias envolvem a sinalização em Libras, a legenda e o áudio em Língua Portuguesa bem como um plano de fundo composto por cenas da história que se modifica no decorrer da contação (figura 7). A sinalização é pausada e os recursos imagéticos permitem a compreensão da temática apresentada no texto. Observamos ainda que por apresentar vídeos em gêneros variados e abordando diferentes assuntos, as histórias contadas nos canais TV INES e TV CES destacam a Libras e permitem o compartilhamento do texto entre surdos e ouvintes de diferentes idades.

O canal "Librando histórias", no ar desde 18 de setembro de 2018, dispõe de histórias que dispõem de diferentes recursos de contação. Há 5 histórias que trazem em comum a Libras em primeiro plano e a presença de áudios em Língua 
Portuguesa. Uma delas é contada com auxílio de materiais que representam o cenário e as personagens (figura 8). Em outra, os contadores assumem o papel de personagens. Como diferencial, os organizadores disponibilizaram atividades de pós-leitura para ensino da Libras e percepções de aspectos apresentados na contação funcionando, portanto, como recursos que podem ser auxiliares à sala de aula ou a serem utilizados no Atendimento Educacional Especializado - AEE.

Há ainda outros canais dentre os quais destacamos que trazem traduções semelhantes tais como o "123Libras" (que não torna acessível as informações dos desenvolvedores na aba do Youtube denominada de cadastro). Esse canal disponibiliza apenas uma contação em Libras, com tradução para a Língua Portuguesa na modalidade oral e plano de fundo com imagens da história (que se modificam a cada trecho sinalizado, complementando a construção do significado).

Vemos uma predominância desses canais que se preocupam em disponibilizar o conteúdo bilíngue relacionados às instituições educacionais, contudo, podemos encontrar contações de qualidade realizadas por sinalizantes da Libras não vinculados à instituições educacionais para surdos, nestes casos, é importante buscar os usuários da língua (professores e intérpretes da Libras) a fim de avaliarem se a produção pode contribuir para o desenvolvimento linguístico do surdo. Neste sentido, não queremos dizer que os aprendizes da língua não podem contribuir neste processo, mas que para os surdos e ouvintes que aprendem a Libras, um texto com características de interlíngua, pode não ser o mais adequado para a compreensão e internalização da Libras. Ressaltamos que a interlíngua compreende o estágio no qual o aprendiz se utiliza de aspectos referentes a sua língua justapostos às características da língua que se deseja aprender (PRIBERAM, 2013), por isso, podem dificultar a compreensão do conteúdo e a internalização da língua.

\subsection{Textos em Português traduzidos para a Libras}

Neste tópico destacamos 2 canais: Educar DPaschoal e o De criança para criança, cujas telas das contações se encontram a seguir.

Figura 9 - A formiga e a mosca

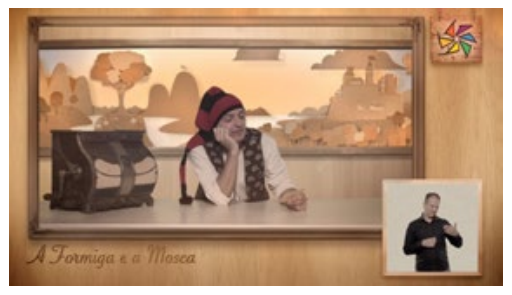

Fonte: Fundação Educar DPaschoal (2011). 
Figura 10 - A galinha que sabia ler

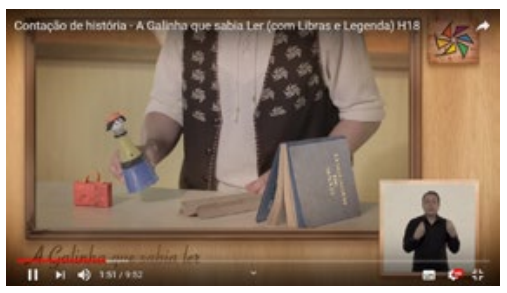

Fonte: Fundação Educar DPaschoal (2011).

Figura 11 - O monstro debaixo da cama

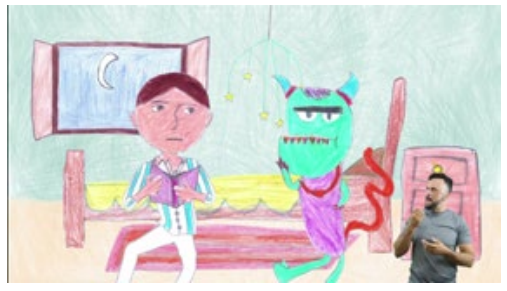

Fonte: De criança para criança (2013).

O canal da "Fundação Educar DPaschoal" (figura 9) intitulado Educar DPaschoal apresenta a interação entre a Língua Portuguesa (em primeiro plano), a Libras (por meio de janela de tradução), imagens (estáticas ou em movimento) para a composição da mensagem. Criado em 28 de setembro de 2011, se apresenta na descrição disponível no YouTube como um espaço para promover leitura.

Ao analisarmos o canal, observamos que não se trata de um espaço destinado apenas à produção de vídeos bilíngues, tendo em vista que a maior parte é produzido em Língua Portuguesa. Entretanto, encontramos um número considerável de produções com essas características: são 20 vídeos com traduções para a Libras em janelas de interpretação, conforme podemos observar na figura 09.

Os elementos recorrentes da contação são o baú, que podemos localizar à esquerda da tela, onde estão guardados os títulos das histórias a serem contadas. Além disso, outros recursos visuais, como por exemplo, fantoches, dedoches, minicenários entre outros são utilizados durante a contação. $\mathrm{Na}$ figura 10, podemos identificar esses recursos podem ser reproduzidos com materiais de baixo custo e com eles o professor pode estimular o reconto, seja em Língua Portuguesa ou em Libras.

O canal "De criança para criança" disponibiliza vídeos de histórias compostas por desenhos infantis (em movimento), contação em Língua Portuguesa (áudio) e sinalização em Libras. São 27 histórias acessíveis entre outros vídeos. O canal existe desde 28 de abril de 2013 e não apresenta descrição escrita, mas no vídeo 
de apresentação informa que foi criado para hospedar textos de um aplicativo utilizado em smartphones e iphones (figura 11).

Apesar do caráter inclusivo, a Libras se apresenta em segundo plano à medida que a figura do contador é um usuário da Língua Portuguesa. Contudo, essas produções funcionam como aproximadores entre surdos e ouvintes, permitindo o compartilhamento das histórias seja no ambiente escolar ou familiar.

Ressaltamos ainda que, no YouTube há diversas produções independentes mas, diante dessas, faz-se necessário o auxílio de um usuário fluente da Libras, conforme discutimos anteriormente, para avaliar o nível de sinalização, tendo em vista que algumas dessas produções foram realizadas como atividade referente à disciplina de Libras, inserida no currículo das licenciaturas (como componente curricular obrigatório) e dos bacharelados (como opcional) a partir do disposto no Art. $3^{\circ}$ do Decreto no $5.626 / 2005$.

Encontramos ainda traduções automáticas realizadas pelo aplicativo denominado VLibras, que realiza a sinalização por meio de um avatar. Apesar de ser um meio de acessibilizar a narrativa, desconsideramos estas histórias por compreender que essa tradução perde as características da contação ao realizar a mesma entonação, pausas e modos de traduzir presentes nos demais textos. Consideramos que o ato de contar histórias pressupõe a ação do contador nos suspenses, nas vozes, nas entonações, acréscimos e supressões que dão vida à narrativa.

\subsection{O trabalho com o texto}

O texto em Libras, para o surdo, permite o contato e a internalização do léxico, da gramática e dos diferentes aspectos que se referem à construção de sentidos. Em um segundo momento, permite o letramento que são as habilidades de uso prático da leitura e da escrita (SOARES, 2002) compreendendo as possibilidades de leitura no âmbito digital. Além dos 10 canais apresentados, que disponibilizam que podem ser acessadas para uso individual, com caráter pedagógico ou para a interação familiar mediada pela leitura, esses vídeos podem ainda ser baixados gratuitamente, permitindo ao usuário compor sua "própria coleção" (ROJO, 2012), ou seja, compor uma biblioteca sinalizada digital contendo os títulos da sua preferência.

Para Valle (2016), a contação pode minimizar o atraso linguístico de surdos que nasceram em famílias de ouvintes, bem como divulgar e valorizar a Língua de Sinais, demonstrando que este sistema linguístico é tão complexo quanto as línguas orais. A autora ressalta ainda que:

\footnotetext{
Incentivar as crianças surdas a adentrarem no universo imagético da literatura pode ocorrer de forma prazerosa, dado isso, a Contação de Histórias em Libras é um meio eficaz para que se realize tal processo, como também, uma forma de auxiliá-las em seu desenvolvimento cognitivo e interacional. (VALLE, 2016, p. 12).
} 
No âmbito escolar, Figueiredo e Guarinello (2013) sugerem que o trabalho com a literatura ocorra em 4 momentos: apresentação e contação; discussão do conto; produção de atividades, divulgação do produto das atividades.

O primeiro momento divide-se em apresentação (com o levantamento dos conhecimentos prévios dos alunos) e a contação ou leitura, envolvendo a Libras (por meio de vídeos ou da contação presencial por um usuário da Libras) ou o português escrito, presente nos livros ou confeccionado. No entanto, as autoras ressaltam a importância de disponibilizar um dicionário Libras/Português para que o estudante possa ter acesso aos significados das palavras que não são do seu conhecimento. O segundo momento é destinado à discussão do conto, e nele, as dúvidas sobre vocabulário e sobre os significados construídos pelos signos presentes no texto são elucidadas. O terceiro momento é destinado para as atividades que podem ser desenvolvidas a partir do texto. E, por fim, no quarto momento, sugere-se a publicação/divulgação do trabalho realizado pelos estudantes. A partir dessa sequência, as possibilidades trazidas pelo texto se ampliam, pois, ao ampliar o vocabulário, o estudante pode compreender outras significações, ao discutir a temática, aprende a compreender a alternância de falas na discussão, a respeitar o ponto de vista do outro e a ampliar, colaborativamente, as suas próprias compreensões. Ao realizar atividades sobre o texto, o estudante/ leitor pode imprimir a sua percepção sobre os fatos, reconstruir as hipóteses a partir do trabalho anteriormente realizado e a se ver como autor das suas próprias narrativas (FIGUEIREDO; GUARINELLO, 2013).

No seio familiar, o conhecimento e uso desses canais podem funcionar como estratégia de aproximação entre os surdos e os seus familiares ouvintes, possibilitando a apropriação da Libras por ambos e, tratando-se dos textos bilíngues, inserindo o surdo, gradativamente, na cultura letrada (em Libras e em Língua Portuguesa).

\section{CONSIDERAÇÓES FINAIS}

A pessoa surda, inserida em um mundo com predominância ouvinte, precisa de recursos diferenciados para ter acesso aos diferentes artefatos culturais disponibilizados na sociedade, entre eles, a literatura. Neste sentido, utilizar uma obra produzida em Libras ou torná-la acessível a esta língua contribui para a significação de práticas de letramento, seja em ambientes escolares ou em não escolares. Com isso, os benefícios pessoais (de autoestima, autorregulação e o ato de lidar com problemas do mundo cotidiano) como também o acesso às formas de pensar e viver de determinada comunidade podem ser internalizadas de maneira lúdica e prazerosa, permeada de experiências visuais.

São obras que estão disponíveis desde 2007 e, que continuam se ampliando, como por exemplo, o canal iniciado em setembro de 2018. Apesar dos avanços, faz-se necessário no investimento de novos espaços de contação (no meio digital, na escola e na família) que estimulem a leitura às pessoas surdas e integrem surdos 
e ouvintes na prática de vivenciar esse momento, sendo ele, mediado ou não pela tecnologia.

Os canais possibilitam ainda ao docente ou familiar que ainda é iniciante no aprendizado da Libras, proporcionar a contação aos surdos e, como benefício, interagir com eles, apropriando-se juntos da Língua de Sinais e transformando a família e a escola em espaços cada vez mais inclusivos e incentivadores da leitura. Essas leituras, em grande parte multimodais, estimularão o uso da tecnologia e da composição de mensagens por diferentes semioses, promovendo tanto o letramento digital quanto a leitura multimodal, presente nos textos ora apresentados.

É necessário assim, que estes textos sejam estudados e divulgados a fim de constituir as práticas de uso da leitura e escrita nesta sociedade em que a tecnologia muda as práticas de leitura e, consequentemente, de participação no mundo. Em trabalhos futuros, pretendemos compreender, por meio de sequências didáticas as contribuições das contações de histórias no meio digital enquanto recurso de apropriação da Libras e como promotora do acesso à Literatura, em diferentes espaços, com surdos e ouvintes.

\section{REFERÊNCIAS}

123LIBRAS. Canal 123 Libras. 2013. Disponível em: < https:/ /www.youtube.com/ channel/UC3Z1T89qMC3731jVOxb0Exw >. Acesso em: 06 dez 2018.

APM CEADA. Canal APM CEADA. 2017. Disponível em: < https://www.youtube. com/channel/UCGFMzmwTqZQxCh5BC6XyVZQ >. Acesso em: 06 dez 2018.

BRASIL. Lei $\mathbf{n}^{\mathbf{0}}$ 10.436, de 24 de abril de 2002. Dispõe sobre a Língua Brasileira de Sinais - Libras e dá outras providências. Disponível em: < http://www.planalto.gov.br/ ccivil_03/LEIS/2002/L10436.htm>. Acesso em: 01 dez. 2018.

Decreto $\mathbf{n}^{\mathbf{0}}$ 5.626, de 22 de dezembro de 2005. Regulamenta a Lei no 10.436 , de 24 de abril de 2002, que dispõe sobre a Língua Brasileira de Sinais - Libras, e o art. 18 da Lei no 10.098, de 19 de dezembro de 2000. Disponível em: < http://www.planalto.gov. br/ccivil_03/_Ato2004-2006/2005/Decreto/D5626.htm>. Acesso em: 01 dez. 2018.

CANDIDO, A. A literatura e a formação do homem. In: ; DANTAS, V.

Textos de intervenção. São Paulo: Editora Duas Cidades, 2002.

CARNEIRO, J. de S. Os gêneros textuais digitais no ensino/aprendizagem da webliteratura... Entreletras, Araguaína, v. 3, n. 1, p. 243-253, jan./jul, 2012.

CAVALCANTI, J. Caminhos da Literatura Infantil e Juvenil: dinâmicas e vivências na ação pedagógica. São Paulo: Paulus, 2002.

DE CRIANÇA PARA CRIANÇA. Canal de Criança para Criança. 2013. Disponível em: <https://www.youtube.com/channel/UC9674g4AazHFEMdHzHJDG5w>. Acesso em: 01 dez 2018. 
FÁVERO, L. L.; KOCH, I. G. V. Linguística Textual: uma introdução. 3 o ed. São Paulo; Cortez, 2009.

FIGUEIREDO, L. C.; GUARINELLO, A. C. Literatura infantil e a multimodalidade no contexto da surdez: uma proposta de atuação. Revista Educação Especial, v. 26 , n. 45, p. 175-193, jan./abr.Santa Maria, 2013. Disponível em: <http://www.ufsm.br/ revistaeducacaoespecial>. Acesso em: 07 dez. 2018.

FUNDAÇÃO EDUCAR DPASCHOAL. 2011. Canal Fundação Educar DPaschoal.

Disponível em: < https://www.youtube.com/user/educardpaschoal/featured >. Acesso em: 15 out. 2018.

GIORDANO, A. A arte de contar histórias e o conto de tradição oral em práticas educativas. Construção psicopedagógica, São Paulo, v. 21, n. 22, p. 26-45, 2013. Disponível em: < http://pepsic.bvsalud.org/scielo.php?script=sci_arttext\&pid=S141569542013000100004\&lng=pt\&nrm=iso >. Acesso em: 01 dez. 2018.

KANASHIRO, E. Canal Elayne Kanashiro. 2009. Disponível em: < https:/ /www. youtube.com/channel/UClwfHdc-lPaPV8_-OPb0-Fw>. Acesso em: 06 dez 2018.

LIBRANDO HISTÓRIAS. Canal Librando Histórias. 2018. Disponível em: < https:/ / www.youtube.com/channel/UC7Dpto9g2CT'T6R9mOKDUzuQ >. Acesso em: 06 dez 2018 .

MÃOS AVENTUREIRAS. Canal Mãos Aventureiras. 2017. Disponível em: < https:// www.youtube.com/channel/UCkmrx_wNCYEGpWnV54LMSlA>. Acesso em: 06 dez. 2018.

MARCUSCHI, L. A. Produção Textual, análise de gênero e compreensão. São Paulo: Parábola Editorial, 2008.

MARCUSCHI, L. A. Gêneros textuais emergentes no contexto da tecnologia digital. In: MARCUSCHI, L. A.; XAVIER, A. C. (Orgs.) Hipertexto e gêneros digitais. São Paulo: Cortez, 2010.

PEREIRA, M. C. da C. et al. Libras: conhecimento além dos sinais. São Paulo: Pearson Pretice Hall, 2013.

INTERLÍNGUA. In: Dicionário Priberam da Língua Portuguesa, 2008-2013.

Disponível em: < http://www.priberam.pt/dlpo/chave>. Acesso em: 21 out. 2013.

ROJO, R. H. Pedagogia dos multiletramentos: diversidade cultural e de linguagens na escola. In ROJO, R. H.; MOURA, E. Multiletramentos na escola. São Paulo: Parábola Editorial, 2012.

ROMANO, R. Canal Rimar Romano. 2007. Disponível em: < https://www.youtube. com/user/Rimar01/featured>. Acesso em: 06 dez. 2018. 
SANTOS, Z. B. A construção de uma leitura multimodal em Língua Estrangeira.

Educação em Destaque. v. 1, n. 2, p. 75-86, Juiz de Fora, 2008.

SISTEMA CHAPLIN. Canal Sistema Chaplin. 2011. Disponível em: < https://www. youtube.com/channel/UCiX7Itpib9iFlfyHHY_MhWA>. Acesso em: 06 dez. 2018.

SLOMSKI, V. G. Educação bilíngue para surdos: concepções e implicações práticas. Curitiba: Juruá, 2010.

SOARES, M. Novas práticas de leitura e escrita: letramento na cibercultura. Educação e Sociedade, Campinas, v. 23, n. 81, p. 143-160, dez, 2002. Disponível em: <http://www. scielo.br/pdf/es/v23n81/13935.pdf>. Acesso em: 01 dez. 2018.

TV CES. Canal TV CES. 2016. Disponível em: < https://www.youtube.com/channel/ UCi8qHwrScueAMc8QkuUiBQA>. Acesso em: 06 dez 2018.

TV INES. Canal TV INES. 2013. Disponível em: <https://www.youtube.com/user/ TVINESoficial>. Acesso em: 06 dez. 2018.

VALLE, J. P. S. A contação de histórias como humanizador de crianças surdas.

2016. TCC. Unidade Acadêmica Especial de Letras e Linguística, Universidade Federal de Goiânia, Catalão, 2016. Disponível em: < https://letras.catalao.ufg.br/up/508/o/Juliana_ Prudente_Santana_do_Valle.pdf $>$. Acesso em: 01 dez. 2018.

VIEIRA, J. A. Novas perspectivas para o texto: uma visão multissemiótica. In:

Reflexões sobre a Língua portuguesa: uma abordagem multimodal. Petrópolis, Vozes, 2007. 